\title{
BMJ Open Factors associated with high levels of glycated haemoglobin in patients with type 1 diabetes: a multicentre study in Brazil
}

\author{
Carine Sousa Andrade, ${ }^{1,2}$ Guilherme Sousa Ribeiro, ${ }^{1,3}$ \\ Carlos Antonio Souza Teles Santos, ${ }^{1,4}$ Raimundo Celestino Silva Neves, ${ }^{1}$ \\ Edson Duarte Moreira $\mathrm{Jr}^{1,5}$
}

To cite: Andrade CS, Ribeiro GS, Santos CAST, et al. Factors associated with high levels of glycated haemoglobin in patients with type 1 diabetes: a multicentre study in Brazil. BMJ Open 2017;7:e018094. doi:10.1136/ bmjopen-2017-018094

- Prepublication history and additional material for this paper are available online. To view these files, please visit the journal online (http://dx.doi. org/10.1136/bmjopen-2017018094).

Received 6 June 2017 Revised 16 0ctober 2017 Accepted 7 November 2017

CrossMark

${ }^{1}$ Gonçalo Moniz Institute, Oswaldo Cruz Foundation, Salvador, Brazil

${ }^{2}$ School of Nutrition, Federal University of Bahia, Salvador, Brazil

${ }^{3}$ Institute of Collective Health, Federal University of Bahia,

Salvador, Brazil

${ }^{4}$ Department of Exact Sciences, State University of Feira de Santana, Feira de Santana, Brazil

${ }^{5}$ Charitable Works Foundation of Sister Dulce, Fundacao Oswaldo Cruz, Salvador, Brazil

Correspondence to

Professor Edson Duarte Moreira Jr; edson@bahia.fiocruz.br

\section{ABSTRACT}

Objective Long-term complications of type 1 diabetes mellitus (DM1) can be prevented with adequate glycaemic control. However, high levels of glycated haemoglobin ( $\mathrm{HbA1C}$ ) occur in $60 \%-90 \%$ of the patients with DM1. Thus, we aimed to investigate the role of sociodemographic, behavioural and clinical factors on the $\mathrm{HbA1c}$ levels of patients with DM1 in Brazil.

Design, setting and participants A cross-sectional study was conducted in ambulatory patients with DM1 aged $\geq 18$ years from 10 Brazilian cities. Sociodemographic, behavioural and clinical data were obtained through interviews.

Main outcome measures $\mathrm{HbA} 1 \mathrm{c}$ level was measured by liquid chromatography. Hierarchical multiple variable linear regression models were used to identify factors correlated with high levels of $\mathrm{HbA1C}$.

Results of 979 patients with DM1, 63.8\% were women, and the mean age was 40 (SD 14.6) years. The mean $\mathrm{HbA1c}$ level was $9.4 \%$ (SD 2.2\%), and $89.6 \%$ of the patients had $\mathrm{HbA} 1 \mathrm{C} \geq 7.0 \%$. Factors independently correlated with increased $\mathrm{HbA1c}$ levels included: lower education, non-participation in diabetes classes/lecture during the year before, having a self-perception of poor adherence to diet and insulin, not having private medical care and not measuring the $\mathrm{HbA} 1 \mathrm{c}$ levels in the prior year. Of note, poor adherence to diet and insulin were the independent factors most strongly associated with high levels of $\mathrm{HbA} 1 \mathrm{c}$ (mean increment in $\mathrm{HbA} 1 \mathrm{c}$ levels of $0.88 \%$ and $1.25 \%$, respectively).

Conclusion Poor glycaemic control, which is common among Brazilian patients with DM1, is associated with lower education, self-perception of insufficient adherence to diet and insulin and inadequate monitoring of $\mathrm{HbA} 1 \mathrm{c}$ levels. Specific actions, particularly those targeting improving adherence to diet and insulin, may contribute to successful management of patients with DM1.

\section{INTRODUCTION}

Type 1 diabetes mellitus (DM1) is characterised by the destruction of the insulin-producing pancreatic $\beta$ cells, leading to a hyperglycaemic state that requires continued
Strengths and limitations of this study

- This cross-sectional, multicentre study included 979 patients with type 1 diabetes mellitus from 10 large Brazilian cities, representing four of the five regions of the country.

- We measured the glycated haemoglobin $(\mathrm{HbA1c})$ levels for all participants in a single laboratory and used the same reference method of liquid chromatography, thus avoiding problems with lack of standardisation reported by other authors.

- In order to identify independent factors associated with increased levels of $\mathrm{HbA1c}$, we applied robust, multiple variable models, using a hierarchical approach according to a previously defined conceptual framework. This method accounts for hierarchical inter-relationships between variables and for the potential underestimation of the effects of distal determinants.

- Data on behavioural and clinical characteristics were collected through interviews, potentially introducing a certain degree of inaccuracy for some answers.

reposition of exogenous insulin in order to prevent life-threatening acute and chronic complications. ${ }^{1}$ The disease's annual incidence varies greatly between countries, ranging from 1.1 to 39.9 per 100000 persons aged 15-19 years ${ }^{2}$ and is globally increasing at a rate of approximately $3 \%$ per year. ${ }^{3}$

Patients with DM1 are at increased risk for cardiovascular disease, periphery nerve damage, nephropathy and retinopathy, resulting in reduced life expectancy for those who are not properly treated. ${ }^{1}$ This risk can be substantially reduced with intensive glycaemic control, aiming for glycated haemoglobin (HbA1c) levels $<6.0 \%{ }^{4}$ However, most patients with DM1 have HbA1c values above the international recom-

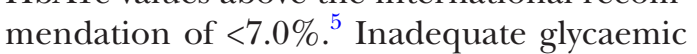
control (HbAlc levels $>7.0 \%$ ) in patients with 
DM1 was observed in $77 \%$ of the participants of a study in the USA in $2016,{ }^{6}$ in $74 \%$ of the study patients in the region of Castilla-La Mancha, Spain in $2012,{ }^{7}$ in $87 \%$ of patients surveyed in Venezuela ${ }^{8}$ and in $84 \%-90 \%$ of the participants of national multicentre studies conducted in Brazil in 2010 and 2015..$^{910}$

A better understanding of the factors that determine glycaemic control is critical to improved management of patients with DM1. However, the majority of studies investigating determinants of glycaemic control enrolled patients with type 2 diabetes mellitus (DM2) or studied patients with DM1 and DM2 combined, despite the fact that challenges to achieve glycaemic control differ between patients with DM1 and DM2, mainly due to the compulsory need of insulin use in patients with DM1. In the few published reports on determinants of glycaemic control in patients with DM1, high levels of HbA1c have been associated with younger age, low educational level, poor adherence to diet, mode of insulin administration and infrequent monitoring of blood glucose. ${ }^{11-15}$ Here, we describe the results of our study in which we investigated the role of sociodemographic, behavioural and clinical characteristics in the levels of HbAlc in a large sample of patients with DM1 in Brazil, a country where $>31000$ persons $<15$ years have DM1 and where the disease burden in adults had not been estimated. ${ }^{16}$

\section{SUBJECTS, MATERIALS AND METHODS \\ Study design and sample selection}

Detailed information on this cross-sectional, multicentre study was published before. ${ }^{9}$ Briefly, the study was conducted in 10 large Brazilian cities, representing four of the five regions of the country (South-east region: Belo Horizonte, Campinas, Rio de Janeiro and São Paulo; South region: Curitiba and Porto Alegre; Midwest region: Brasilia and North-east region: Salvador, Fortaleza and Recife). These cities are the largest in their respective regions, and nine of them were ranked among the most populous municipalities in Brazil. To pursue the selection of the diabetes medical centres, we requested the Brazilian Diabetes Association to identify in each of the study city a list of candidate centres, selected because of previous experience in conducting epidemiological research and where a large number of adult patients are treated for diabetes (minimum of 300 patients per month). In each city, two diabetes centres (20 centres in total) were invited to participate in the study: 5 university-affiliated hospitals, 11 general public hospitals and 4 not-for-profit private hospitals. All invited centres accepted and were included in the study.

From February 2006 to March 2007, we invited patients fulfilling the eligibility criteria to participate in the study during 30 consecutive days in each of the centres. To be eligible for study enrolment, patients had to be 18 years of age or older and report a prior medical diagnosis of DM1. Patients who had participated in other research in the 3 months preceding the study were excluded. All patients were informed about the study aims, procedures and risks and signed an informed consent prior to inclusion.

\section{Data collection}

Trained interviewers who were not part of the medical centres staff interviewed the participants using a structured questionnaire (online supplementary file) to obtain data on demographic and socioeconomic indicators, self-perception of diet and insulin treatment adherence, attendance to diabetes education lectures, participation in associations of patients with diabetes and clinical characteristics. The clarity of the questionnaire was assessed through pilot interviews in a sample of patients with DM1 previously to study initiation. Data on education attainment (primary school or less, complete or incomplete secondary/high school or at least some college level education) and on race/skin colour were self-reported. Data on self-perception of diet adherence and of insulin adherence were collected using the following ordinal scale: poor/fair, good or excellent. Clinical data included self-referred height and weight, time since first diagnosis of diabetes, number of insulin doses per day, frequency of self-monitoring of blood glucose as well as frequencies, in the previous 12 months, of consultation in public and private medical service facilities, consultation with an endocrinologist, prior hypoglycaemic episodes, prior hospitalisations due to ketoacidosis and $\mathrm{HbAlc}$ measurements. Interviews were conducted in a private room and lasted $20-25 \mathrm{~min}$. The response rate was $84 \%$ (ranging from $78 \%$ to $95 \%$ ).

\section{Measurement of HbA1c}

A blood sample was collected from participants at enrolment and tested by automated high-performance liquid chromatography to determine HbAlc levels. All exams were performed in the same laboratory, according to standard procedures. The HbAlc levels data were reported as mean and SD and, categorically, as a frequency of $<7.0 \%$, $7.0 \%-8.9 \%, 9.0 \%-10.9 \%$ or $\geq 11.0 \%$. We considered glycaemic control to be inadequate when the HbA1c concentration was $\geq 7.0 \%{ }^{5}$

\section{Statistical analysis}

Data were double entered into a computerised database using the EPI INFO V.3.04 software system (Centers for Disease Control and Prevention, Atlanta, USA). Subsequently, the two databases were electronic compared with validate the accuracy and internal consistency of the data. Statistical analyses were performed using STATA V.12 (StataCorp).

Participants' characteristics were presented using means and SD for continuous variables and frequencies for categorical variables. Patients' body mass index (BMI) was calculated (by dividing weight in kilograms by the square of height in metres) and classified as eutrophic $\left(<25.0 \mathrm{~kg} / \mathrm{m}^{2}\right)$ and overweight/obese $\left(\geq 25.0 \mathrm{~kg} / \mathrm{m}^{2}\right)$, according to the WHO criteria. ${ }^{17}$ 


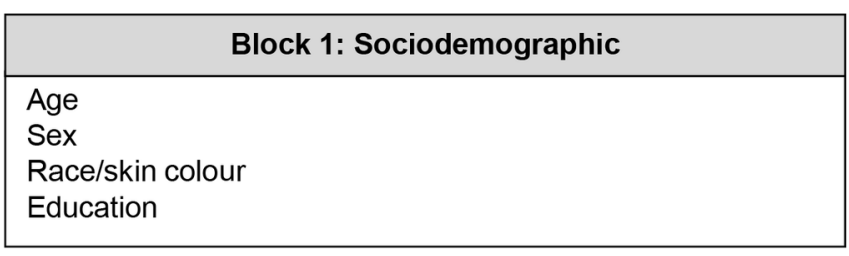

\begin{tabular}{|l|}
\hline \multicolumn{1}{|c|}{ Block 2: Behavioural } \\
\hline $\begin{array}{l}\text { Self-perception of adherence to: } \\
\text { Diet } \\
\text { Insulin }\end{array}$ \\
Participation in: \\
Lecture in Diabetes in the last 12 months \\
Association of patients with diabetes
\end{tabular}

\section{Outcome: Glycated haemoglobin (HbA1c) levels}

Figure 1 Hierarchical model for determinants of high levels of $\mathrm{HbA1c}$ in patients with type 1 diabetes. HbA1c, glycated haemoglobin.

We applied bivariate and multiple variables linear regression models to estimate the effect of the independent variables on the level of HbA1c. Variables with a significant association at $\mathrm{P}$ value of $\leq 0.20$ in the bivariate analyses were included in robust, multiple variable models using a hierarchical approach according to a previously defined conceptual framework (figure 1). A conceptual framework is a theoretical model that describes the hierarchical relationships between explanatory variables and an outcome. This approach is considered an appropriate strategy for assessing disease determinants in multiple variable analyses because it handles complex hierarchical inter-relationships between variables and accounts for the potential underestimation of the effects of distal determinants (ie, factors that typically do not determine the outcome directly, but do determine by other intermediate factors). ${ }^{18}$

The hierarchical model grouped variables into three blocks (figure 1). Block 1 contained socioeconomic variables, such as education level and race/skin colour. Block 2 contained behavioural variables, such as attendance to diabetes class/lectures, participation in associations of patients with diabetes and self-perception of adherence to diet and insulin treatment. Block 3 comprised of clinical characteristics, including BMI, time since first diagnosis of diabetes, number of insulin doses per day, and frequency of self-monitoring of blood glucose, consultation with an endocrinologist and HbA1c measurement in the previous 12 months (figure 1).

A backward elimination strategy was then performed for each block. Block 1 variables that were significantly correlated with $\mathrm{HbAlc}$ serum levels at a $\mathrm{P}$ value $\leq 0.05$ were maintained in the subsequent backward elimination model with block 2 variables. Using the same approach, block 2 variables that were significantly correlated with HbAlc serum levels at a $P$ value $\leq 0.05$ were maintained in the subsequent backward elimination model with block 3 variables. Finally, block 3 variables with a $\mathrm{P}$ value $\leq 0.05$ were defined as factors independently correlated with the HbA1c levels. Variables from block 1 to block 2 that were selected to be included in following models were considered to be significantly correlated with $\mathrm{HbA1c}$ levels, regardless of their $\mathrm{P}$ value in the subsequent models. Sex and age were included in all models to ensure adjustments to these factors at all stages of the multiple variable analyses. We used the Akaike Information Criterion (AIC) to estimate the goodness of fit of the successive adjusted models.

\section{RESULTS}

Of the 979 patients with DM1 enrolled in the study, 625 $(63.8 \%)$ were women, and $296(30.2 \%)$ were $18-29$ years, $412(42.1 \%) 30-49$ years and $271(27.7 \%) \geq 50$ years (table 1$)$. About half $(488,49.8 \%)$ of the patients were white, and $398(40.8 \%)$ had not studied beyond the primary school level. The south-east region of Brazil accounted for $611(62.4 \%)$ participants. Although all the diabetes centres were affiliated with the Brazilian public healthcare system, $95(9.7 \%)$ of the patients reported that they had also received private assistance during the past 12 months.

The diabetes complications most frequently reported by the study participants were retinopathy $(427,43.6 \%)$, followed by neuropathy $(381,39.2 \%)$ and nephropathy $(207,21.1 \%)$. Episodes of ketoacidosis and hypoglycaemia in the previous year were common, affecting 248 (25.3\%) and $497(50.8 \%)$ patients, respectively. The majority (887, $89.6 \%$ ) of patients had inadequate glycaemic control (HbAlc $\geq 7.0 \%$ ), and the mean HbAlc level was $9.4 \%$ (SD $2.2 \%)$.

Bivariate analysis pointed to a correlation of higher levels of HbA1c with black race, lower education attainment, self-perception of fair/poor adherence to diet and to insulin treatment, not participating in diabetes class/ lectures during the previous year and never having participated in associations of patients with diabetes (table 2). In addition, patients who reported that in the previous year had neither regular medical appointments, nor consultations with an endocrinologist, private consultations or healthcare delivered in the same diabetes centre had significantly higher HbAlc. Finally, patients not performing regular self-monitoring of blood glucose, those with no measure of HbAlc during the previous year and patients receiving less than four doses of insulin per day also had higher levels of HbA1c. 
Table 1 Sociodemographic and clinical characteristics of 979 Brazilian patients with type 1 diabetes, Brazil

\begin{tabular}{|c|c|}
\hline Characteristics & n (\%) \\
\hline \multicolumn{2}{|l|}{ Sociodemographics } \\
\hline \multicolumn{2}{|l|}{ Age (years) } \\
\hline $18-29$ & $296(30.2)$ \\
\hline $30-49$ & $412(42.1)$ \\
\hline$\geq 50$ & $271(27.7)$ \\
\hline Sex female & $625(63.8)$ \\
\hline \multicolumn{2}{|l|}{ Race/skin colour } \\
\hline White & $488(49.8)$ \\
\hline Mixed & $286(29.2)$ \\
\hline Black & $122(12.5)$ \\
\hline Other & $83(8.5)$ \\
\hline \multicolumn{2}{|l|}{ Education* } \\
\hline At least some college & $154(15.8)$ \\
\hline Secondary/high school & $424(43.4)$ \\
\hline Primary school or less & $398(40.8)$ \\
\hline \multicolumn{2}{|l|}{ Brazilian region } \\
\hline South-east & $611(62.4)$ \\
\hline North-east & $174(17.8)$ \\
\hline South & $104(10.6)$ \\
\hline Centre-west & $90(9.2)$ \\
\hline \multicolumn{2}{|l|}{ Clinical } \\
\hline \multicolumn{2}{|l|}{ Type of service for medical care in the last year } \\
\hline Public & $884(90.3)$ \\
\hline Private & $95(9.7)$ \\
\hline \multicolumn{2}{|l|}{$\mathrm{BMI}\left(\mathrm{kg} / \mathrm{m}^{2}\right) \dagger$} \\
\hline$<25.0$ & $502(52.5)$ \\
\hline$\geq 25.0$ & $455(47.5)$ \\
\hline \multicolumn{2}{|l|}{ Clinical complications } \\
\hline Hypoglycaemic episodes in the last year & $497(50.8)$ \\
\hline Ketoacidosis hospitalisation in the last year & $248(25.3)$ \\
\hline \multicolumn{2}{|l|}{ Reported complications } \\
\hline Retinopathy & $427(43.6)$ \\
\hline Neuropathy $\ddagger$ & $381(39.2)$ \\
\hline Nephropathy & $207(21.1)$ \\
\hline Angina§ & $129(13.2)$ \\
\hline Vasculopathy§ & $125(12.8)$ \\
\hline \multicolumn{2}{|l|}{ Laboratory } \\
\hline \multicolumn{2}{|l|}{$\mathrm{HbA1c}(\%)$} \\
\hline$<7.0$ & $102(10.4)$ \\
\hline 7.0-8.9 & $366(37.4)$ \\
\hline $9.0-10.9$ & $287(29.3)$ \\
\hline$>11.0$ & $224(22.9)$ \\
\hline
\end{tabular}

${ }^{*}$ Data available for 976 patients.

†Data available for 957 patients.

‡Data available for 973 patients.

$\S$ Data available for 977 patients.

BMI, body mass index; HbA1c, glycated haemoglobin.
The first multiple variable model, built with the socioeconomic variables (model A, table 3), showed that for each 1 year rise in age, HbA1c level was, on average, reduced by $0.01 \%(\beta=-0.013,95 \% \mathrm{CI}-0.025$ to -0.002$)$ and that education level only up to primary school was correlated with higher HbA1c levels ( $\beta=0.565$, 95\% CI 0.154 to 0.977 ). The second multiple variable model, which combined the behavioural variables with the selected variables from model A (model B, table 3), found that not participating in diabetes class/lecture during the previous year $(\beta=0.503$, $95 \%$ CI 0.208 to 0.799 ) and a self-perception of fair/poor adherence to diet ( $\beta=0.889,95 \%$ CI 0.446 to 1.332$)$ and to insulin therapy ( $\beta=1.385,95 \% \mathrm{CI} 0.764$ to 2.007 ) were also positively correlated with HbA1c levels. The third multiple variable model, which incorporated the clinical variables with those selected in model B (model C, table 3), found that not consulting at a private clinic during the previous year $(\beta=0.545,95 \% \mathrm{CI} 0.021$ to 1.069$)$ and having no HbAlc measurement performed in the previous year ( $\beta=0.770,95 \%$ CI 0.418 to 1.122 ) were positively correlated with the HbAlc levels. It is noteworthy to mention that the effect of education over $\mathrm{HbAlc}$ levels was reduced with the subsequent introduction of further variables from blocks 2 to 3 (models $\mathrm{B}$ and $\mathrm{C}$ ), indicating that the effect of education on glycaemic control was mediated by the behavioural and clinical variables incorporated into the model.

\section{DISCUSSION}

Our results indicate that sociodemographic, behavioural and clinical factors in patients with DM1 are independently associated with high levels of HbAlc. Of note, self-reported poor adherence to diet was strongly associated with elevated HbAlc levels. This finding is of special relevance because adherence to diet is a modifiable factor, possibly accomplished by specific actions targeting those non-compliant to dietary recommendations. These findings add valuable information for a better understanding of the barriers to achieve adequate glycaemic control in adult patients with DM1.

The American Diabetes Association recommends that patients with a recent diagnosis of diabetes and without major complications or prior history of severe hypoglycaemic episodes should target HbA1c levels of $<6.5 \%$, whereas patients with advanced microvascular and macrovascular complications or comorbidities aim towards HbAlc levels of $<8.0 \% .^{5}$ This recommendation is supported by studies conducted over two decades ago, showing that poor glycaemic control is associated with microvascular and macrovascular complications in patients with diabetes. ${ }^{45}$ Despite that, the majority of patients with DM1 worldwide have inadequate glycaemic control. ${ }^{71920}$ In our study, we found that the mean HbAlc level was $9.4 \%$, the same result observed in another multicentre, DM1 study, conducted in 20 Brazilian cities between 2008 and $2010 .{ }^{10}$ This study also found that the quality of life of patients with DM1 was inversely related to the levels of HbAlc. 
Table 2 Factors associated with $\mathrm{HbA1c}$ levels in Brazilian patients with type 1 diabetes

Independent variable

Block 1-sociodemographic

Age (years)

\begin{tabular}{|c|c|c|c|c|}
\hline $18-29$ & 296 & $9.35(2.36)$ & Ref & 0.198 \\
\hline $30-49$ & 412 & $9.54(2.28)$ & $0.186(-0.146$ to 0.517$)$ & \\
\hline$\geq 50$ & 271 & $9.24(1.95)$ & $-0.118(-0.484$ to 0.248$)$ & \\
\hline \multicolumn{5}{|l|}{ Sex } \\
\hline Male & 354 & $9.25(2.08)$ & Ref & 0.122 \\
\hline Female & 625 & $9.48(2.29)$ & $0.229(-0.061$ to 0.518$)$ & \\
\hline \multicolumn{5}{|l|}{ Race/skin colour } \\
\hline White & 488 & $9.26(2.10)$ & Ref & 0.058 \\
\hline Mixed & 286 & $9.32(2.33)$ & $0.133(-0.191$ to 0.456$)$ & \\
\hline Black & 122 & $9.84(2.34)$ & 0.576 (0.136 to 1.017$)$ & \\
\hline Other & 83 & $9.62(2.31)$ & $0.361(-0.155$ to 0.877$)$ & \\
\hline \multicolumn{5}{|l|}{ Education } \\
\hline At least some college & 154 & $9.13(1.82)$ & Ref & 0.002 \\
\hline Secondary/high school & 424 & $9.21(2.15)$ & $0.084(-0.325$ to 0.492$)$ & \\
\hline Primary school or less & 398 & $9.70(2.40)$ & 0.565 (0.154 to 0.977$)$ & \\
\hline \multicolumn{5}{|l|}{ Block 2-behavioural } \\
\hline \multicolumn{5}{|c|}{ Self-perception of adherence to diet } \\
\hline Excellent & 129 & $8.79(2.22)$ & Ref & $<0.001$ \\
\hline Good & 327 & $9.13(2.09)$ & $0.344(-0.103$ to 0.792$)$ & \\
\hline Fair/poor & 523 & $9.72(2.25)$ & 0.931 (0.508 to 1.354$)$ & \\
\hline \multicolumn{5}{|c|}{ Self-perception of adherence to insulin } \\
\hline Excellent & 750 & $9.28(2.12)$ & Ref & $<0.001$ \\
\hline Good & 144 & $9.59(2.30)$ & $0.315(-0.074$ to 0.703$)$ & \\
\hline Fair/poor & 62 & $10.82(2.49)$ & 1.543 (0.978 to 2.107$)$ & \\
\hline \multicolumn{5}{|c|}{$\begin{array}{l}\text { Participation in lecture for diabetes in the last } \\
\text { year }\end{array}$} \\
\hline Yes & 345 & $9.11(2.09)$ & Ref & $<0.001$ \\
\hline No & 540 & $9.67(2.31)$ & $0.549(0.247$ to 0.850$)$ & \\
\hline \multicolumn{5}{|c|}{$\begin{array}{l}\text { Participation in association of patients with } \\
\text { diabetes }\end{array}$} \\
\hline Yes, still participate & 116 & $9.09(1.88)$ & Ref & 0.023 \\
\hline Yes, but no more participate & 124 & $9.02(1.80)$ & $-0.067(-0.627$ to 0.492$)$ & \\
\hline No, I never participated & 713 & $9.51(2.32)$ & $0.418(-0.016$ to 0.851$)$ & \\
\hline \multicolumn{5}{|l|}{ Block 3-clinical } \\
\hline \multicolumn{5}{|l|}{$\operatorname{BMI}\left(\mathrm{kg} / \mathrm{m}^{2}\right)$} \\
\hline$<25.0$ & 502 & $9.45(2.29)$ & Ref & 0.273 \\
\hline$\geq 25.0$ & 455 & $9.30(2.08)$ & $-0.156(-0.435$ to 0.123$)$ & \\
\hline \multicolumn{5}{|c|}{ Regular medical visit in the last year } \\
\hline Yes & 878 & $9.34(2.19)$ & Ref & 0.020 \\
\hline No & 101 & $9.89(2.42)$ & 0.541 (0.084 to 0.998$)$ & \\
\hline \multicolumn{5}{|c|}{ Endocrinologist visit in the last year } \\
\hline Yes & 800 & $9.32(2.15)$ & Ref & 0.014 \\
\hline No & 177 & $9.77(2.50)$ & 0.453 (0.091 to 0.814$)$ & \\
\hline
\end{tabular}

Continued

Participants, n \% (SD)

B Coefficient $(95 \% \mathrm{Cl}) \quad$ P value

HbA1c means in 
Table 2 Continued

\section{Independent variable}

HbA1c means in

Participants, $n \quad \%$ (SD)

B Coefficient $(95 \% \mathrm{Cl}) \quad$ P value

Diabetes care in specialised service in the last

year

\begin{tabular}{|c|c|c|c|c|}
\hline Yes & 661 & $9.32(2.18)$ & Ref & 0.120 \\
\hline No & 318 & $9.56(2.29)$ & $0.236(-0.061$ to 0.533$)$ & \\
\hline \multicolumn{5}{|c|}{ Diabetes care in private clinic in the last year } \\
\hline No & 884 & $9.46(2.27)$ & $0.586(0.117$ to 1.055$)$ & \\
\hline \multicolumn{5}{|c|}{ Diabetes care in the same service } \\
\hline No & 57 & $10.10(2.64)$ & 0.735 (0.142 to 1.328$)$ & \\
\hline \multicolumn{5}{|c|}{ Time since diabetes onset (years) } \\
\hline$<10$ & 261 & $9.43(2.66)$ & Ref & 0.326 \\
\hline $10-19$ & 307 & $9.52(2.11)$ & $0.094(-0.273$ to 0.460$)$ & \\
\hline$\geq 20$ & 408 & $9.27(1.97)$ & $-0.115(-0.497$ to 0.192$)$ & \\
\hline Yes, when decompensated & 160 & $9.72(2.28)$ & $0.463(0.080$ to 0.845$)$ & \\
\hline No & 151 & $9.74(2.46)$ & 0.489 (0.097 to 0.881$)$ & \\
\hline \multicolumn{5}{|l|}{ Number of insulin doses per day } \\
\hline Four times & 168 & $8.91(1.97)$ & Ref & 0.001 \\
\hline Three times & 290 & $9.38(2.10)$ & 0.477 (0.062 to 0.892$)$ & \\
\hline Two times or less & 505 & $9.61(2.29)$ & 0.707 (0.326 to 1.088$)$ & \\
\hline \multicolumn{5}{|c|}{ Measurement of $\mathrm{HbA1c}$ in the last year } \\
\hline Yes & 533 & $9.10(1.93)$ & Ref & $<0.001$ \\
\hline No & 184 & $10.00(2.48)$ & 0.901 (0.576 to 1.226$)$ & \\
\hline
\end{tabular}

Bivariate linear regression analyses.

$\mathrm{BMI}$, body mass index; HbA1c, glycated haemoglobin.

In our multiple variable model including only the sociodemographic variables, we found that patients whose highest level of educational attainment was primary school had a mean level of HbAlc $0.77 \%$ greater than patients with at least some college level education. The relation between lower educational attainment of patients with DM1 and higher levels of HbA1c has been previously reported. ${ }^{712}$ However, a noteworthy finding of our study is that the correlation coefficient between educational levels and HbA1c levels decreased after we incorporated the behavioural variables (model B) and almost disappeared when the clinical factors were included (model C). The differences observed in the education level correlation coefficients among these models indicate that the effect of lower education on the level of HbAlc is possibly mediated by behavioural (adherence to diet and insulin and participation in lecture for diabetes in the last year) and, especially, by clinical factors (attendance to private clinics and measurement of HbAlc, both in the year before). This original finding is of relevance because it highlights that the influence of lower education on inadequate glycaemic control can be surpassed if patients with DM1 have good adherence to diet and treatment and receive proper monitoring of $\mathrm{HbAlc}$ levels.

Regarding the behavioural factors, we found that participation in diabetes education programmes was associated with better glycaemic control, consistent with previous studies. In a case-control study conducted in Saudi Arabia, patients with DM1 or DM2 who had received monthly counselling about the disease had significantly reduced HbAlc levels compared with those who had received counselling only at the beginning of the study. ${ }^{21}$ In another single-arm, pre-post cohort study, aiming to estimate the impact of improving the knowledge, skills and confidence in self-management of DM1, the average HbA1c levels were significantly reduced from baseline to follow-up measurements. ${ }^{22}$ The mechanisms by which diabetes education programmes help achieve a better 


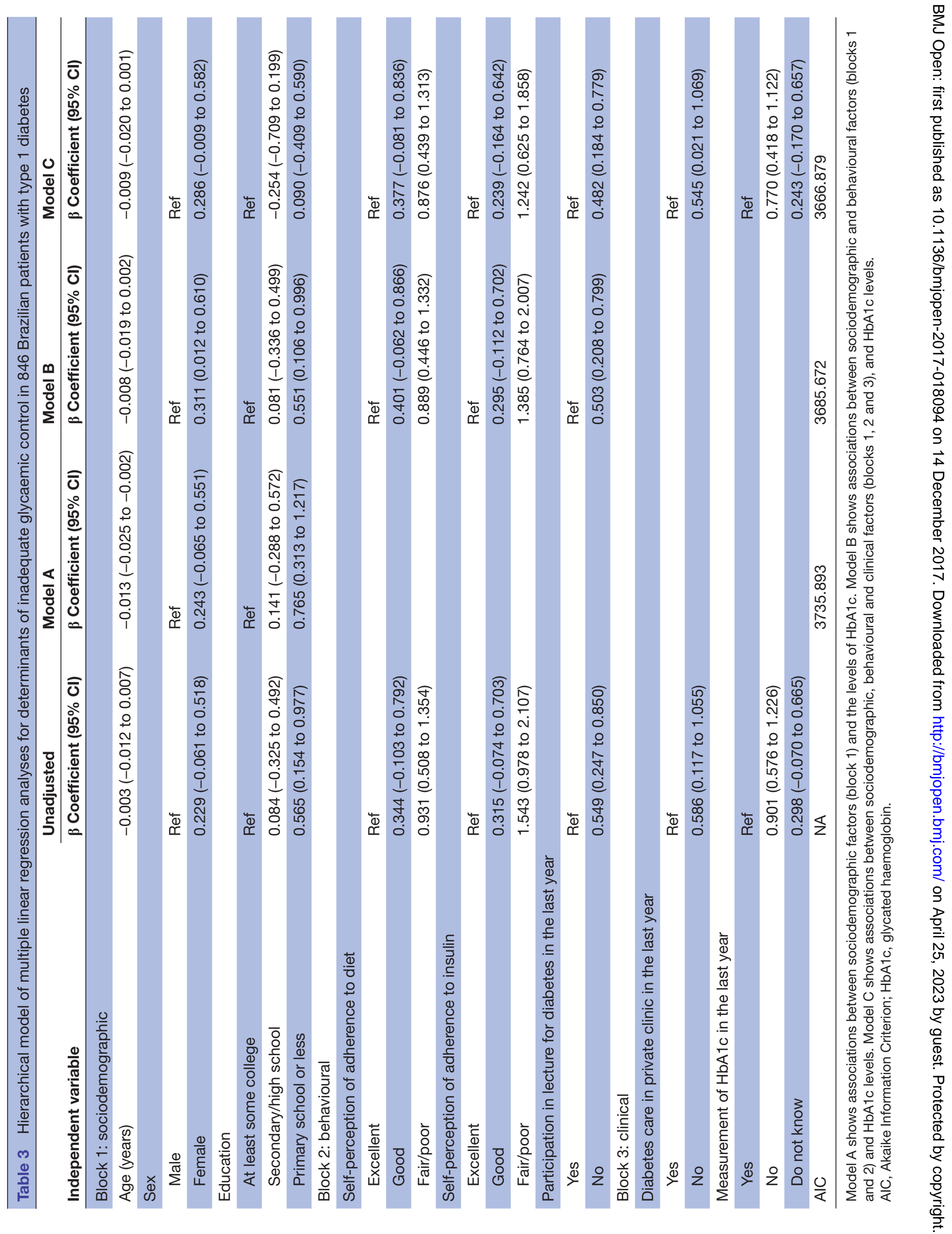


glycaemic control are likely diverse and may include provision of knowledge about the disease, aid in developing skills and techniques for disease self-management and support for adoption of healthy eating and lifestyle habits. Our findings reinforce the importance of policies and practices that challenge the traditional medical care of DM1 and include educational activities to empower patients to achieve goals for glycaemic control.

A lower degree of self-perceived adherence to diet and insulin therapy was also strongly associated with higher levels of HbA1c among our study patients. These findings are in accordance with other studies of patients with DM1, in which the average HbA1c was significantly lower among patients who followed dietary recommendations, compared with those who did not. ${ }^{14} 23$ A study that enrolled both DM1 and DM2, insulin-treated patients also found after adjusting for confounders that better glycaemic control was associated with adherence to a dietary plan that included greater daily ingestion of fruits and vegetables, but not with adherence to insulin therapy. ${ }^{19}$ However, Gastal et $a l^{24}$ found that better scores in a diabetes self-care scale evaluating diabetes general management, diet, exercise, care with feet, glycaemic monitoring, insulin administration and detection, prevention or treatment of hypoglycaemia/hyperglycaemia were associated with lower HbAlc values. Thus, additional evidence supports our findings that adherence to both diet and insulin regimens are essential for glycaemic control and for subsequent prevention of disease complications and early death. We recommend that health professionals involved in DM1 care devote substantive efforts to motivate patients to follow diet recommendations and treatment prescriptions. Whenever possible, they should try to simplify the treatment regimen and work to guarantee a proper understanding of their patients about the disease and its management. Further observational studies, aiming to identify factors that influence adherence to both diet and insulin, are warranted. In addition, experimental trials should compare the efficacy of different strategies to improve patients' compliance to diet and treatment. Such strategies may include different motivational approaches to improve adherence, as well as the use of different insulin delivery devices.

Unfortunately, we did not collect detailed data on diet and food consumption, which would allow a better understanding of its role on glycaemic control. Even though, our finding of an inverse relation between the degree of self-perceived adherence to diet and HbAlc levels suggests that following specific alimentary recommendations have a direct contribution to glycaemic control. Several actions may help reinforcing the role of diet adherence to glycaemic control, such as a close follow-up by a multidisciplinary health team (including nutritionists, social assistants, psychologists and other professionals), provision of patients' education, spouse and family support, encouraging diet adherence ${ }^{25}$ and the use of digital media and electronic devices, such as smart phone self-care 'apps'. ${ }^{26}$
Some studies suggest that patients with DM1 undergoing close monitoring of diabetes through regular HbA1c measurements, blood glucose self-monitoring and regular medical appointments had lower levels of HbAlc. ${ }^{132728}$ We found in bivariate analysis, but not in multiple variable analyses, that those self-monitoring blood glucose on a regular basis had lower HbAlc levels. The failure of our multiple variable analyses to show this association may derive from the method that we used to obtain data on blood glucose self-monitoring, which was self-reported, not relying on diaries or other more accurate sources to quantify the daily frequency of self-monitoring in a typical day. However, our finding that patients who did not measure the HbAlc level in the previous year had greater levels of HbA1c, even after adjustment for other variables, does support the notion that a careful disease monitoring is critical for an adequate glycaemic control. Thus, regular monitoring of glycaemic levels should be an essential chapter of policies and programmes designed to provide improved care for patients with DM1.

We also found that patients who had not received diabetes medical care at private services presented significantly higher HbAlc levels than those who had. This result raises concerns because the Brazilian public health system provides universal medical care for the majority of the population with diabetes in the country. Training the public health professionals for diabetes care and ensuring better infrastructure and access to universal assistance for patients with diabetes are critical collective actions that need to be attained in order to decrease the high percentage of patients with DM1 with inadequate glycaemic control. Specific actions may include providing multidisciplinary professional teams for diabetes care and increasing access to the most advanced insulin therapies, such as insulin pump, and to self-monitoring of blood glucose. Use of insulin pumps in Brazil is not covered by the public national health system, and it is incipient even for patients treated at private health services because insulin pumps are not produced in the country and the imported product is sold at an unaffordable price (>US\$4000). ${ }^{29} 30$

This study has some limitations. First, the cross-sectional design does not allow for establishing a temporal relation between the factors associated with high levels of HbAlc. Therefore, a thorough follow-up of patients with DM1 through a cohort study is warranted and may help elucidate whether the factors we found to be associated with higher HbA1c levels are causally related to poor glycaemic control. Second, except for the HbA1c measurement, all the patients' data, including the behavioural and clinical characteristics, were collected through interviews, potentially introducing a certain degree of inaccuracy for some answers. However, interviews are widely used in epidemiological and clinical studies of diabetes, and our results are consistent with those of previous studies that used self-reported answers. ${ }^{10}$ In addition, self-reported data have been shown to have high agreement with medical records for several questions, such as type of diabetes, family history 
of diabetes, therapeutic regimen and disease complications. ${ }^{31}$ Although inaccurate answers on type of diabetes might have led to inclusion of some patients with insulin-treated DM2 in the study population, we expect this number to be small, having minimal impact on our findings and conclusions. Third, typical DM1 onset happens during childhood and adolescence, but our study sample only included patients $\geq 18$ years and was obtained in reference diabetes care centres. Therefore, we might have introduced a selection bias, with participants likely having a longer disease duration, a greater number of complications and, possibly, worse glycaemic control. In addition, the study patients were not randomly selected. However, as the sample of patients with DM1 was consecutively enrolled during 30 days in 20 diabetes centres from 10 large cities in four different regions of Brazil, it is reasonable to assume that the factors associated with a poor glycaemic control among the studied patients can be generalised to patients with DM1 seeking care in large urban centres in the country. On the other hand, in our study, we measured the HbA1c levels for all participants in a single laboratory and used the same reference method of liquid chromatography, thus avoiding problems with lack of standardisation reported by other authors.

In summary, our findings support the concept that multiple and distinct factors, such as sociodemographic, behavioural and clinical drivers, act together to influence the glycaemic control in patients with DM1. Encouraging patients' adherence to diet and to insulin treatment is critical for achieving optimum levels of HbAlc. Health education programmes to inform and engage patients in their treatment, as well as ensuring periodic medical monitoring and measurement of HbAlc, are important additional measures. Reinforcing these recommendations for public health policies and clinical guidelines may translate into improved glycaemic control in DM1.

Acknowledgements The authors would like to thank the team members in the collection of blood samples, interviews with patients and performing $\mathrm{HbA1c}$ tests and the study investigators: Adriana C Forti, MD; Ana B V Mendes, MD; Antônio R Chacra, MD; Celio C Borges, MD; Debora V Soares, MD; Edson P Brum, MD; Elza M S Constantino, MD; Francisco A Oliveira, MD; Freddy Eliaschewitz, MD; Hermelinda Pedrosa, MD; João A S Fittipaldi, MD; Jorge Gross, MD; Jose E P Oliveira, MD; Lucia Cordeiro, MD; Lucia P E Souza, MD; Marcia Nery, MD; Marcos Tambascia, MD; Maria C C de Almeida, PhD; Maria R Calsolari, MD; Reinaldo B M Machado, MD; Reine Chaves, MD; Rosane Kupfer, MD; Ruy Lyra, MD; Saulo Cavalcante, MD and Silmara Leite, MD. We also thank Professor Uriel Kitron for his valuable review of the manuscript.

Contributors Conceived and designed the experiments: EDM, CSA and GSR. Analysis and interpretation of data: CSA, GSR, CASTS, RCSN and EDM. Wrote the paper: CSA and GSR. Reviewed and approved the final version of the manuscript: CSA, GSR, CASTS, RCSN and EDM.

Funding The Brazilian Study of Diabetes Control was funded by Pfizer, Brazil. CSA received scholarship from the Coordination for the Improvement of Higher Education Personnel (CAPES), Brazilian Ministry of Education. GSR and EDM received scholarships from the National Council for Scientific and Technological Development (CNPq).

Competing interests EDM was a consultant for Pfizer Inc.

Patient consent Obtained.

Ethics approval Hospital Santo Antônio Ethics Committee (approval no.32/05).
Provenance and peer review Not commissioned; externally peer reviewed.

Data sharing statement The datasets analysed during the current study may be available from the corresponding author on reasonable request.

Open Access This is an Open Access article distributed in accordance with the Creative Commons Attribution Non Commercial (CC BY-NC 4.0) license, which permits others to distribute, remix, adapt, build upon this work non-commercially, and license their derivative works on different terms, provided the original work is properly cited and the use is non-commercial. See: http://creativecommons.org/ licenses/by-nc/4.0/

(c) Article author(s) (or their employer(s) unless otherwise stated in the text of the article) 2017. All rights reserved. No commercial use is permitted unless otherwise expressly granted.

\section{REFERENCES}

1. Drouin P, Blickle JF, Charbonnel B, et al. Diagnosis and classification of diabetes mellitus. Diabetes Care 2010;33:S62-9.

2. Diaz-Valencia PA, Bougnères $P$, Valleron AJ. Global epidemiology of type 1 diabetes in young adults and adults: a systematic review. BMC Public Health 2015;15:255.

3. Tuomilehto J. The emerging global epidemic of type 1 diabetes. Curr Diab Rep 2013;13:795-804.

4. Nathan DM, Genuth S, Lachin J, et al. The effect of intensive treatment of diabetes on the development and progression of longterm complications in insulin-dependent diabetes mellitus. $N$ Engl $J$ Med 1993;329:977-86.

5. George Bakris M, Blonde MD LL, Andrew JM, et al. Standards of medical care in diabetes - 2015. Diabetes Care J Clin Appl Res Educ 2015;38:S1-99.

6. McCarthy M, Funk M, Grey M. Ideal cardiovascular health in adults with type 1 diabetes. Nurs Res 2016.

7. Sastre J, Pinés PJ, Moreno J, et al. Situación de control metabólico y pautas de tratamiento en pacientes con diabetes tipo 1 en CastillaLa Mancha: estudio de diabetes tipo 1 en Castilla-La Mancha. Endocrinología y Nutrición 2012;59:539-46.

8. Moreira ED, Neves RC, Nunes ZO, et al. Glycemic control and its correlates in patients with diabetes in Venezuela: results from a nationwide survey. Diabetes Res Clin Pract 2010;87:407-14.

9. Mendes AB, Fittipaldi JA, Neves RC, et al. Prevalence and correlates of inadequate glycaemic control: results from a nationwide survey in 6,671 adults with diabetes in Brazil. Acta Diabetol 2010;47:137-45.

10. Braga de Souza AC, Felício JS, Koury CC, et al. Health-related quality of life in people with type 1 Diabetes Mellitus: data from the Brazilian Type 1 Diabetes Study Group. Health Qual Life Outcomes 2015;13:204.

11. Paris CA, Imperatore G, Klingensmith $\mathrm{G}$, et al. Predictors of insulin regimens and impact on outcomes in youth with type 1 diabetes: the SEARCH for Diabetes in Youth study. J Pediatr 2009;155:183-9.

12. Nádas J, Putz Z, Fövényi J, et al. Cardiometabolic risk and educational level in adult patients with type 1 diabetes. Acta Diabetol 2009;46:159-62.

13. Pfützner A, Weissmann J, Mougiakakou S, et al. Glycemic Variability Is Associated with Frequency of Blood Glucose Testing and Bolus: Post Hoc Analysis Results from the ProAct Study. Diabetes Technol Ther 2015;17:392-7.

14. Davison KA, Negrato CA, Cobas R, et al. Relationship between adherence to diet, glycemic control and cardiovascular risk factors in patients with type 1 diabetes: a nationwide survey in Brazil. Nutr $J$ 2014;13:19.

15. Petitti DB, Klingensmith GJ, Bell RA, et al. Glycemic control in youth with diabetes: the SEARCH for diabetes in Youth Study. J Pediatr 2009;155:668-72.

16. Patterson C, Guariguata L, Dahlquist G, et al. Diabetes in the young - a global view and worldwide estimates of numbers of children with type 1 diabetes. Diabetes Res Clin Pract 2014;103:161-75.

17. Bailey KV, Ferro-Luzzi A. Use of body mass index of adults in assessing individual and community nutritional status. Bull World Health Organ 1995;73:673-8.

18. Victora CG, Huttly SR, Fuchs SC, et al. The role of conceptual frameworks in epidemiological analysis: a hierarchical approach. Int $J$ Epidemiol 1997;26:224-7.

19. Angamo MT, Melese BH, Ayen WY. Determinants of glycemic control among insulin treated diabetic patients in Southwest Ethiopia: hospital based cross sectional study. PLoS One 2013;8:e61759.

20. Colom C, Chico A, Carreras G, et al. Control glucémico y complicaciones crónicas a 20 años del comienzo de la diabetes tipo 
1. Resultados de una unidad especializada. Avances en Diabetología 2015;31:113-9.

21. Ba-Essa EM, Mobarak El, Alghamdi A, et al. Intensified glucose selfmonitoring with education in Saudi DM patients. Int J Clin Exp Med 2015;8:19374-80.

22. Speight J, Holmes-Truscott E, Harvey DM, et al. Structured type 1 diabetes education delivered in routine care in Australia reduces diabetes-related emergencies and severe diabetes-related distress: The OzDAFNE program. Diabetes Res Clin Pract 2016;112:65-72.

23. Mehta SN, Volkening LK, Anderson BJ, et al. Dietary behaviors predict glycemic control in youth with type 1 diabetes. Diabetes Care 2008;31:1318-20.

24. Gastal DA, Pinheiro RT, Vazquez DP. Self-efficacy scale for Brazilians with type 1 diabetes. Sao Paulo Med J 2007;125:96-101.

25. Leong A, Rahme E, Dasgupta K. Spousal diabetes as a diabetes risk factor: a systematic review and meta-analysis. BMC Med 2014;12:12:12.

26. Joshi R, Joshi D, Cheriyath P. Improving adherence and outcomes in diabetic patients. Patient Prefer Adherence 2017;11:271-5.
27. Miller KM, Beck RW, Bergenstal RM, et al. Evidence of a strong association between frequency of self-monitoring of blood glucose and hemoglobin A1c levels in T1D exchange clinic registry participants. Diabetes Care 2013;36:2009-14.

28. Jin SM, Baek JH, Suh S, et al. Factors associated with greater benefit of a national reimbursement policy for blood glucose test strips in adult patients with type 1 diabetes: A prospective cohort study. J Diabetes Investig 2017;2.

29. Minicucci WJ. Uso de bomba de infusão subcutânea de insulina e suas indicações. Arquivos Brasileiros de Endocrinologia \& Metabologia 2008;52:340-8.

30. Cocolo AC. Bomba de insulina nacional facilitará controle do diabetes tipo 1. Entre Teses 2017;8:38-41. http://www.unifesp. $\mathrm{br} / \mathrm{reitoria} / \mathrm{dci} /$ entreteses/item/2854-bomba-de-insulina-nacionalfacilitara-controle-do-diabetes-tipo-1

31. Løvaas KF, Cooper JG, Sandberg S, et al. Feasibility of using selfreported patient data in a national diabetes register. BMC Health Serv Res 2015;15:553. 